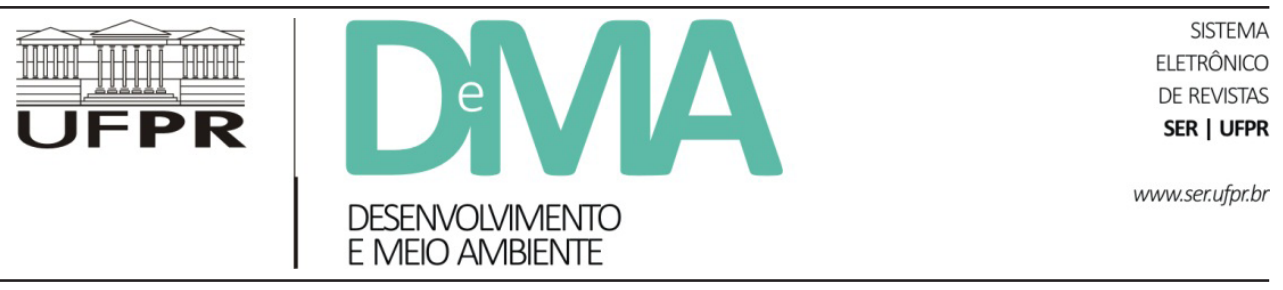

\title{
Os fatores de repercussão da cadeia produtiva do dendê no desenvolvimento local do Baixo Tocantins
}

\section{The Repercussion Factors of the Palm Oil Chain Production in the Local Development of Baixo Tocantins}

\author{
Vanilda Araújo FERREIRA ${ }^{1 *}$, Antônio Cordeiro SANTANA ${ }^{2}$, Nírvia RAVENA ${ }^{1}$, Cyntia Meireles OLIVEIRA $^{2}$ \\ ${ }^{1}$ Universidade Federal do Pará (UFPA), Belém, PA, Brasil. \\ ${ }^{2}$ Universidade Federal Rural da Amazônia (UFRA), Belém, PA, Brasil. \\ *E-mail de contato: vaniaraujo.f@gmail.com
}

Artigo recebido em 31 de março de 2016, versão final aceita em 30 de novembro de 2016.

RESUMO: O objetivo deste trabalho foi identificar os fatores econômicos, sociais e ambientais produzidos pelo "agronegócio do dendê (Elaeis guianensis Jacq.)", a partir da integração da agricultura familiar à atividade, avaliando seus efeitos sobre a dinâmica do desenvolvimento local no Baixo Tocantins. As informações foram coletadas em pesquisa de campo com os sujeitos sociais vinculados à cadeia. Os resultados revelaram que a governança da cadeia, a sustentabilidade social, a sustentabilidade ambiental, a mudança climática e a qualificação técnica são os fatores que repercutem negativamente sobre a organização do espaço econômico, social e ambiental das famílias agricultoras. Os fatores latentes identificados permitiram construir o Índice de Sustentabilidade do Desenvolvimento Local (ISDL) para avaliar o grau de influência da atividade na configuração da qualidade de vida das pessoas. O ISDL evidenciou a incapacidade do dendê de tornar-se a alternativa socioeconômica e ambiental capaz de gerar emprego, renda e melhoria na qualidade de vida das populações locais.

Palavras-chave: agricultura integrada; agroindústria do dendê; análise multivariada; Amazônia.

ABSTRACT: The objective of this paper was to identify economic, social and environmental factors produced by "palm oil (Elaeis guianensis Jacq.) agrobusiness", from the integration of family agriculture to the activity, evaluating its effect on the dynamics of local development in Baixo Tocantins. The data were collected on field research with the social subjects linked to the chain. The results revealed that the chain governance, the social sustainability, the environmental sustainability, the climate change and the technical qualification are the factors that negatively affect the organization of socio-economic and environmental space of the farming families. The latent factors allowed us to construct the Local Development Sustainability Index (LDSI) to evaluate the degree of influence of the productive chain of palm oil in configuring people's quality of life. The LDSI has highlighted the palm oil inability to become a socio-economic and environmentally sustainable alternative, creating employment opportunities, income and improvement in the local population quality of life.

Keywords: integrated agriculture; agro-industry of palm oil; multivariate analysis; Amazon. 


\section{Introdução}

No Brasil, a monocultura do dendê (Elaeis guianensis Jacq.) foi promovida a política de Estado por meio de ações governamentais como o Zoneamento Agroecológico da Cultura da Palma de Óleo e o Programa de Produção Sustentável de Óleo de Palma no Brasil (Brasil, 2010). É concebida como uma das alternativas para respaldar programas de fomento ao desenvolvimento local inclusivo e sustentável.

No Pará, a Agropalma, empresa de capital nacional, destaca-se como a maior produtora de óleo de palma. No sistema de produção integrada, a Agropalma é pioneira e detentora de expertise na região. A parceria, estabelecida por contrato com agricultores familiares do entorno da empresa, iniciou com a perspectiva de consolidar nova dinâmica de produção sustentável com o apoio de políticas direcionadas à agricultura familiar no estado do Pará.

Contudo, pesquisas evidenciaram que o sistema produtivo do óleo de palma adotado na Indonésia, na Malásia e na Colômbia foi acompanhado de desmatamentos de áreas de florestas nativas, conflitos sociais e agrários, ameaças à fauna silvestre, expropriação das populações tradicionais, dentre outros problemas (Pye, 2008; Feintrenie et al., 2010; McCarthy, 2010).

Na Amazônia, embora o cultivo do dendê tenha sido implantado com o objetivo de promover o desenvolvimento de forma sustentável e inclusiva, estudos constataram que a atividade vem se desenvolvendo a elevados custos socioambientais para as populações locais. Foi identificado um quadro crescente de concentração da terra pelo complexo agroindustrial de óleo de palma, sustentado por novas alianças entre empresas transnacionais, o Estado e as elites locais da região, além de expropriações e degradação dos ecossistemas (Acevedo, 2010; Beckhouse, 2013; Monteiro, 2013; Nahum \& Santos, 2013; 2014; Sousa, 2015).
Mesmo diante dos problemas causados pela expansão da dendeicultura na Amazônia, as ações governamentais continuam estimulando a expansão da atividade na região. A assinatura do protocolo para estimular a cadeia produtiva de palma de óleo no estado do Pará, em 26 de agosto de 2014, pelo governo do estado, mostra o apoio público a esse segmento de produção (Protocolo..., 2014).

Silva (2015) assinala que o avanço do "agronegócio" na Amazônia brasileira está relacionado com a racionalidade fundada no tempo-espaço e na lógica da globalização, que gera transformações socioeconômicas e ambientais significativas onde se instala e, consequentemente, produz fragmentações nas coerências territoriais locais e impõe a lógica global das grandes empresas.

Há, na literatura, um consenso de que a resposta local aos desafios da globalização pressupõe a autonomia da comunidade, que pode ser alcançada à medida que se evidenciam as maiores potencialidades locais e o grau de organização e engajamento da sociedade em prol da consolidação de um projeto que articule o local com o global. Nessa perspectiva, o desenvolvimento local ocorre como um valor social (Harvey, 1996; Barquero, 2001; Vasconcelos et al., 2007; Sen, 2010).

$\mathrm{Na}$ abordagem deste trabalho, o desenvolvimento é concebido como um processo de promoção de liberdades substantivas, traduzidas empiricamente por oportunidades econômicas e garantias de liberdade política, de benefícios sociais, de transparência e segurança protetora. As diversas instituições sociais devem ser avaliadas segundo a sua contribuição para a expansão de direitos dos indivíduos, vistos como agentes ativos de mudança, e não como recebedores passivos de benefícios (Sen, 2010; Borzel \& Risse, 2015).

O desenvolvimento fundado na justiça social deve visar ao desenvolvimento da pessoa como 
cidadã, garantindo o acesso do indivíduo ao "mínimo existencial". Este diz respeito não somente aos direitos sociais para assegurar a existência, mas às condições necessárias para que o cidadão entenda e tenha a possibilidade de exercer de forma fecunda os seus direitos e liberdades fundamentais na sociedade democrática e a escolha de suas alternativas de desenvolvimento (Dworkin, 2000; Rawls, 2005).

Decorridos 12 anos de experiência no sistema integrado de produção, é salutar que as comunidades agricultoras avaliem a capacidade da "parceria" em promover melhorias nos componentes que elas reconhecem como fundamentais para o desenvolvimento local. A liberdade melhora o potencial das pessoas para cuidar de si mesmas e para influenciar o mundo. É, portanto, elemento fundamental para o desenvolvimento (Sen, 2010).

Com efeito, este trabalho busca responder à seguinte questão: qual a magnitude e a forma de influência dos principais fatores que determinam a dinâmica dos produtores familiares integrados ao Projeto Dendê, na perspectiva do desenvolvimento local das comunidades no entorno da Agropalma?

Para responder a essa questão, o objetivo da pesquisa foi aplicar a análise fatorial como procedimento metodológico para identificar os fatores socioeconômicos e ambientais gerados pelo Projeto Dendê, avaliando como estão influenciando a dinâmica de desenvolvimento local no Baixo Tocantins.

\section{Material e métodos}

\section{1. Área de estudo}

O nordeste paraense foi definido como referência empírica desta pesquisa, por constituir-se em área estratégica de expansão da lavoura do dendê no estado do Pará, dada a proximidade dos portos e da capital paraense, Belém, bem como as condições geofísicas favoráveis. E, notadamente, por estampar na paisagem da região as grandes transformações socioeconômicas e ambientais produzidas pelo "agronegócio do dendê".

A pesquisa contemplou a área de atuação da empresa Agropalma, formada pelos municípios de Acará, Tailândia e Moju. A pesquisa de campo limitou-se às comunidades de Arauaí, Água Preta e Apei, no município de Moju, no nordeste paraense, por concentrarem o maior número de agricultores familiares com contrato firmado com a empresa (Figura 1).

\subsection{Coleta de dados}

A pesquisa de campo foi utilizada como fonte de informação para a coleta dos dados, por meio da aplicação de questionários semiestruturados, no período de 4 de maio a 10 de julho de 2015. Nesse mesmo período foi aplicada a técnica de entrevistas em profundidade, visando complementar as informações dos questionários.

O universo da pesquisa foi constituído de 192 famílias produtoras de dendê que tinham contratos firmados com a Agropalma no período de 2002 até 2014. Daí foi extraída uma amostra ${ }^{1}$ probabilística de 50 agricultores, distribuídos nas comunidades de Água Preta, Arauaí e Apei, no município de Moju.

\subsection{Análise de dados}

\subsubsection{Análise fatorial exploratória}

Sobre essa amostra da população foi aplicada a análise fatorial. Os dados foram processados no

\footnotetext{
${ }^{1}$ A amostra foi representativa, considerando $95 \%$ de confiança na proporção da população $(p=0,23$ sucesso e $p=0,77$ insucesso) e erro amostral de $10 \%$.
} 


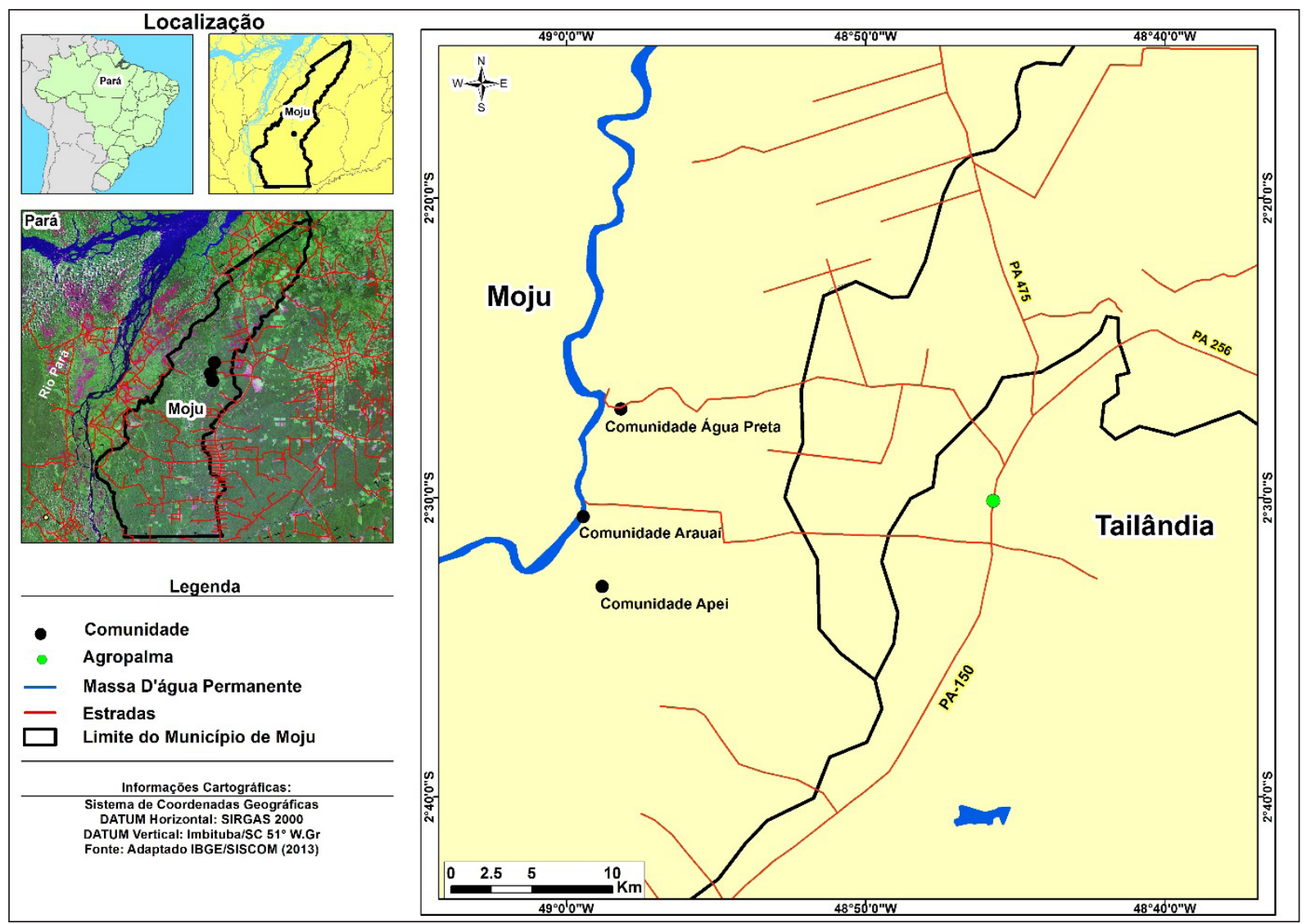

FIGURA 1 - Mapa de localização das comunidades de Água Preta, Arauaí e Apei, Moju/Pará. FONTE: Elaboração da autora (2016).

software SPSS Statistics 18, em função da necessidade de aplicação de testes de singularidade das matrizes e de adequação da amostra aos métodos estatísticos. Para atingir um padrão teoricamente mais significativo e mais simples de interpretar os fatores, utilizou-se o método de rotação ortogonal varimax. Na apresentação dos resultados, utilizou-se a planilha Excel para a construção das tabelas. A análise fatorial exploratória (AFE) consiste em uma abordagem estatística que pode ser usada para analisar inter-relações entre um grande número de variáveis e explicar essas variáveis em termos de suas dimensões inerentes comuns (fatores). $\mathrm{O}$ objetivo é encontrar uma forma de resumir as informações do fenômeno estudado em um conjunto menor de variáveis estatísticas, com perda mínima de informações (Santana, 2005; Hair et al., 2009).

Sob a perspectiva da AFE, assume-se que um grupo entre todas as variáveis apresenta alta correlação entre si, mas baixas correlações com as variáveis de outros grupos. Concebe-se, portanto, que esse grupo de variáveis define um único fator ou dimensão latente. 
Sendo assim, o modelo AFE pode ser utilizado para a identificação dos fatores que estruturam a cadeia produtiva do dendê a partir das variáveis que definem e influenciam as dinâmicas socioeconômicas e ambientais das comunidades de Água Preta, Arauaí e Apei.

Foram selecionadas 11 variáveis, que abrangem aspectos inerentes à dinâmica socioeconômica e ambiental das comunidades pesquisadas, a partir da integração da agricultura familiar à cadeia produtiva do dendê, quais sejam: cumprimento das cláusulas contratuais $(\mathrm{X} 1)$, atendimento às reivindicações (X2), qualidade de vida da família (X3), benefício social (X4), renda da família (X5), tamanho da família (X6), satisfação com o dendê (X7), temperatura da área (X8), nível de água dos rios (X9), regularidade de chuva (X10) e nível de escolaridade (X11).

Especificamente, buscou-se avaliar: a) o nível de escolaridade dos agricultores familiares, pois a parceria é celebrada por contrato e o agricultor precisa conhecer e compreender o alcance das cláusulas contratuais que regem a produção, saber que irá contrair dívidas junto ao banco e deve conhecer as condições do financiamento adquirido, além de outros conhecimentos necessários para lidar com as inovações técnicas, agora incorporadas ao processo produtivo; b) o grau de satisfação dos agricultores com relação ao cumprimento das cláusulas contratuais por parte da Agropalma; c) o atendimento às reivindicações dos agricultores com relação à participação na tomada de decisões, à melhoria das condições de trabalho e ao incentivo e aperfeiçoamento de iniciativas; d) melhorias na qualidade de vida das famílias agricultoras, incluindo oportunidades econômicas, liberdades políticas, conservação do patrimônio histórico e cultural, condições habilitadoras como nutrição satisfatória, boa saúde, educação básica, moradia apropriada, acesso a água tratada e saneamento básico; e) a relação entre as variáveis tamanho da família, renda da família e benefício social para avaliar a capacidade da renda oriunda exclusivamente do dendê de suprir satisfatoriamente as demandas das famílias agricultoras sem a complementação de qualquer benefício social; $f$ ) as condições ambientais adequadas à boa qualidade de vida na área, captadas por meio das variáveis temperatura da área, qualidade e nível de água dos rios, regularidade de chuva; e g) o grau de satisfação dos agricultores integrados com o desempenho da atividade de dendê.

De acordo com Santana et al. (2014), na especificação formal do modelo AFE, assume-se que cada variável observada é uma combinação linear dos fatores latentes extraídos, tal que cada variável aleatória $i \in\{1, \ldots \mathrm{N}\}$ pertence a uma população homogênea com média $\mu_{i}$.

$$
\mathrm{y}_{i-} \mu_{i=} \psi_{y} \mathrm{f}_{i}+\mathrm{e}_{i}
$$

em que $\psi_{y}$ é a matriz de pesos fatoriais ( $\left.\mathrm{p} \times 1\right), \mathrm{f}_{i}$ é o vetor de fatores latentes ( $\mathrm{p}$ x q) e e é o vetor de erros aleatórios ( $\mathrm{p} \times 1)$. Assume-se a independência entre $\mathrm{f}_{i} \mathrm{e} \mathrm{e}_{i}$, com $\mathrm{V}\left(\mathrm{f}_{i}\right)=\Sigma_{f} \mathrm{e} \mathrm{V}\left(\mathrm{e}_{i}\right)=\Sigma_{e}$, dando origem à matriz de covariância de $\mathrm{y}_{i}$, dada por $\mathrm{V}\left(\mathrm{y}_{i}\right)$ $=\psi_{y} \Sigma_{f} \psi_{y}^{\prime}+\Sigma_{e}$.

O primeiro termo do lado direito representa a parcela de covariância atribuída aos fatores comuns, e o segundo termo, a covariância atribuída ao erro. Assim, a comunalidade, ou parcela de variância comum apresentada na variável, é dada pelos elementos da diagonal principal de $\psi_{y} \Sigma_{f} \psi_{y}^{\prime}$, enquanto a variância específica do erro é dada pelos elementos da diagonal principal de $\Sigma_{e}$ (Santana et al., 2014).

Quanto à adequação da amostra de dados ao método de análise fatorial, foram aplicados os testes de Bartlett e de Kaiser-Meyer-Oklin (KMO), por corresponderem a procedimentos estatísticos que permitem aferir a qualidade das correlações entre as variáveis e seguir com a AFE (Santana et al., 2014). 
O número de fatores necessários para descrever os dados foi determinado pelo método de Kaiser, que recomenda a escolha daqueles cuja variância explicada é superior a 1 (um). Ademais, segundo Hair et al. (2009), o número de fatores extraídos deve explicar pelo menos $60 \%$ da variância total dos dados. As variáveis a serem incluídas no modelo fatorial devem apresentar uma comunalidade superior a 0,5 , ou seja, pelo menos $50 \%$ de sua variância deve ser explicada pelos fatores comuns extraídos (Santana et al., 2014).

Assim, a identificação das variáveis associadas a cada fator foi realizada com base na magnitude e na significância das cargas fatoriais de cada variável. Desse modo, uma dada variável pertence ao fator cuja carga fatorial for mais alta.

\subsubsection{Indicador de desenvolvimento local}

De posse dos fatores latentes estimados, foi possível construir um Índice de Sustentabilidade do Desenvolvimento Local (ISDL), para avaliar o grau de influência socioeconômica e ambiental da cadeia produtiva do dendê no processo de desenvolvimento local do Baixo Tocantins.

O ISDL, conforme Santana (2007), é dado por:

$$
I S D L_{j}=\sum_{j=1}^{q}\left(\frac{\lambda_{j}}{\sum \lambda} F P_{j}\right)
$$

em que $\lambda$ é a variância explicada por cada fator e $\Sigma \lambda$ é a soma total da variância explicada pelo conjunto de fatores comuns. $\mathrm{O}$ escore fatorial foi padronizado $(F P)$ para que os valores fossem todos positivos. A fórmula utilizada foi a seguinte:

$$
F P_{j}=\left(\frac{F_{j}-F_{\text {min }}}{F_{\text {max }}-F_{\text {min }}}\right) ;(j=1, \ldots, q)
$$

em que $F_{\text {máx }}$ e $F_{\text {min }}$ são os valores máximo e mínimo observados para os escores fatoriais associados às famílias entrevistadas.

Para facilitar a interpretação dos resultados, foram estabelecidos os seguintes intervalos de variação do ISDL: valor superior a 0,7 é considerado alto; valor superior a 0,5 e inferior ou igual a 0,7 é considerado intermediário; valor superior a 0,3 e inferior ou igual a 0,5 é baixo; e valor inferior ou igual a 0,3 é considerado muito baixo.

\section{Resultados e discussão}

\subsection{Análise fatorial}

A AFE foi utilizada fundamentalmente para incorporar o rigor científico necessário à definição dos graus de significância dos fatores socioeconômicos e ambientais gerados pela cadeia produtiva do dendê que influenciam a dinâmica de desenvolvimento local (Santana et al., 2014).

A matriz de correlação apresentou determinante diferente de zero. Logo, admite inversa, e a solução resultante é única e teoricamente representativa do fenômeno. A adequação da amostra ao modelo de análise fatorial foi aferida pela estatística de KMO e pelo teste de Bartlett (Tabela 1). O KMO foi de 0,528, superior ao limite aceitável de 0,50. O teste de esfericidade de Bartlett foi significativo a $1 \%$, indicando que a amostra é adequada à análise fatorial.

As cargas fatoriais estimadas apresentaram significância a 1\%. Todas as comunalidades situaram-se acima de 0,50 , o que atesta a importância das variáveis na definição das dimensões latentes. Por fim, os fatores extraídos explicaram $72,62 \%$ da variância total dos dados. Dessa forma, considera-se que o modelo AFE foi bem especificado e os resultados representam o fenômeno estudado. 
TABELA 1 - Matriz de cargas fatoriais do modelo de sustentabilidade da integração ao dendê, após a rotação ortogonal pelo método Varimax, Pará, 2015

\begin{tabular}{lcccccc}
\hline \multicolumn{1}{c}{ Variáveis } & Fator $\mathbf{1}$ & Fator $\mathbf{2}$ & Fator $\mathbf{3}$ & Fator 4 & Fator 5 & Comunalidade \\
\hline Cláusula contrato & $\mathbf{0 , 7 3 0}$ & $-0,042$ & $-0,169$ & $-0,182$ & 0,284 & 0,677 \\
Atende à reivindicação & $\mathbf{0 , 8 0 0}$ & 0,109 & 0,223 & 0,132 & $-0,072$ & 0,724 \\
Qualidade vida fam. & $\mathbf{0 , 6 2 8}$ & $-0,288$ & $-0,080$ & 0,309 & $-0,279$ & 0,657 \\
Benefício social & $-0,099$ & $\mathbf{- 0 , 8 4 0}$ & 0,123 & $-0,054$ & $-0,140$ & 0,753 \\
Renda fam. dendê & 0,071 & $\mathbf{0 , 5 3 6}$ & 0,379 & $-0,500$ & 0,047 & 0,688 \\
Tamanho da família & $-0,262$ & $\mathbf{0 , 7 1 1}$ & $-0,062$ & 0,113 & $-0,261$ & 0,659 \\
Satisfação com dendê & $-0,433$ & 0,103 & $\mathbf{0 , 6 0 5}$ & $-0,216$ & $-0,374$ & 0,751 \\
Temperatura & $-0,058$ & 0,137 & $\mathbf{0 , 6 5 0}$ & 0,589 & 0,188 & 0,826 \\
Nível água dos rios & 0,126 & $-0,210$ & $\mathbf{0 , 7 6 4}$ & 0,069 & 0,038 & 0,650 \\
Regularidade de chuvas & 0,141 & 0,089 & 0,081 & $\mathbf{0 , 8 5 3}$ & 0,039 & 0,764 \\
Nível de escolaridade & $-0,008$ & $-0,015$ & 0,026 & 0,064 & $\mathbf{0 , 9 1 3}$ & 0,838 \\
\hline Soma de cargas ao quadrado & $\mathbf{1 , 8 7 7}$ & $\mathbf{1 , 6 7 7}$ & $\mathbf{1 , 6 2 7}$ & $\mathbf{1 , 5 4 2}$ & $\mathbf{1 , 2 6 5}$ & $\mathbf{7 , 9 8 8}$ \\
Percentual do traço $(\mathbf{\%})$ & $\mathbf{1 7 , 0 6 8}$ & $\mathbf{1 5 , 2 4 2}$ & $\mathbf{1 4 , 7 8 9}$ & $\mathbf{1 4 , 0 1 6}$ & $\mathbf{1 1 , 5 0 3}$ & $\mathbf{7 2 , 6 1 8}$ \\
\hline
\end{tabular}

Adequação da amostra: teste $\mathrm{KMO}=0,528$; teste de Bartlett $(\chi 255 \mathrm{gl})=100,247$ (p-valor $=0,0000)$

FONTE: Dados da pesquisa. Elaboração própria.

Conforme esperado, após a rotação ortogonal pelo método varimax, a solução fatorial apresentou cinco fatores. Dessa forma, o fator 1 explicou a maior parcela da variância total $(17,06 \%)$ e contempla as variáveis $\mathrm{X} 1, \mathrm{X} 2$ e X3. O fator 2 explicou $15,24 \%$ da variância e está representando a associação das variáveis X4, X5 e X6. O fator 3 explicou $14,78 \%$ e integra as variáveis $\mathrm{X} 7, \mathrm{X} 8$ e X9. Já o fator 4 , que explicou $14,01 \%$ da variância, está associado à variável X10. Por fim, o fator 5 explicou $11,50 \%$, sendo definido pela variável X11.

\subsection{Fatores de impactos socioeconômicos e ambientais}

Com base na percepção dos agricultores sobre a importância dos fatores social, econômico e ambiental que influenciam a dinâmica de desenvolvimento local no Baixo Tocantins, foi possível identificar os cinco fatores mais importantes.

$O$ primeiro fator representou a interação das variáveis: cumprimento das cláusulas contratuais, atendimento às reivindicações dos agricultores $\mathrm{e}$ melhoria da qualidade de vida das famílias, todos com sinais positivos altos.

O descumprimento das cláusulas contratuais e o não atendimento às demandas dos agricultores estão repercutindo negativamente na qualidade de vida das famílias integradas, marcada por uma relação de subordinação do agricultor em relação à empresa. Esse cenário evidencia que as relações de poder e as forças que determinam a governança da cadeia produtiva do dendê são controladas de forma unilateral pela Agropalma. Portanto, o fator pode ser denominado governança da cadeia. 
O segundo fator foi definido pelas variáveis benefício social, com carga negativa, renda da família após o dendê e tamanho da família, com sinais positivos, demonstrando mais um entrave para o desenvolvimento local, contrariando a finalidade social da integração dos pequenos agricultores à produção de óleo de palma pela empresa, qual seja, gerar renda para as comunidades de agricultores (Brasil, 2010).

O benefício social recebido pela maioria das famílias integradas atua como força contrária ao nível de renda advindo exclusivamente da dendeicultura. A relação entre as variáveis renda da família após o dendê e tamanho da família repercute negativamente na qualidade de vida, dado que não é suficiente para prover as necessidades básicas das famílias, compostas, em média, de quatro a seis pessoas. Isso ocorre devido à discrepância existente entre o baixo valor recebido e o tamanho relativamente grande das famílias. Esse fator pode ser denominado sustentabilidade social.

O terceiro fator incluiu o efeito das variáveis satisfação com o dendê, temperatura e nível das águas dos rios, todos com sinais positivos altos. Esse cenário indica que o atual quadro de insatisfação com a atividade do dendê entre os agricultores não está associado apenas ao desempenho econômico da atividade. Há uma preocupação real das famílias com a manutenção de condições socioambientais adequadas para garantir melhor qualidade de vida na região. A elevação da temperatura na área e a redução do nível da água dos rios e igarapés da região nos últimos anos foram apontadas pela maioria dos agricultores como impactos diretamente relacionados à expansão da cultura do dendê na localidade. "[...] É uma planta que pede muita água, a raiz é profunda. Quando a plantação está nova, não tem quem aguente ficar no dendezal depois das dez da manhã” (informação verbal). A tendência a essas alterações foi identificada por Nahum e Santos (2013), com relação aos impactos socioambientais advindos da expansão do cultivo de palma na região.

Esse fator demonstra que, na Amazônia, o uso da terra pela monocultura do dendê está em consonância com os princípios da sustentabilidade fraca, pois não alia a preservação do capital natural a imperativos éticos. Está orientada pela lógica neoclássica do crescimento econômico, cujo funcionamento é garantido por um sistema econômico de fluxo circular ou mercado de concorrência perfeita, autorregenerador e autoalimentado, não gerando externalidades ou custo ao bem-estar da sociedade (Faucheux \& Noel, 1995).

Por se tratar de um fator que reflete claramente os elevados danos socioambientais causados pela utilização do ativo terra pela cadeia produtiva do dendê nas comunidades agricultoras, pode ser denominado sustentabilidade ambiental.

O quarto fator constituiu-se da variável regularidade de chuvas, com carga positiva e elevada. Os agricultores identificaram, recentemente, uma sensível redução na regularidade das chuvas na área. Essa variável pode estar fortemente relacionada com os percentuais consideráveis de desmatamento na região, decorrentes da abertura de ramais para o escoamento da produção, da retirada ilegal de madeira das áreas de reserva no interior das pequenas propriedades ou do entorno da empresa, e até mesmo da manutenção da técnica tradicional de corte e queima na lavoura branca para complementar a renda do agricultor.

Esse argumento se fortalece quando é considerada a importância do serviço ecossistêmico do recurso floresta, especialmente o serviço de regulação ambiental, contribuindo para a manutenção da vida no planeta. Esse serviço está relacionado às características regulatórias dos processos ecos- 
sistêmicos, como manutenção da qualidade do ar e das águas, regulação da temperatura, precipitação e outros aspectos climáticos que incidem nas mudanças em níveis globais ou locais (Costanza, 2007).

Por se tratar de um fator que enseja uma preocupação com a preservação do capital natural e da sua capacidade de provisão de serviços por meio de uma gestão sustentável pelo sistema econômico, pode ser chamado de mudança climática.

O quinto fator representa o nível de escolaridade e pode ser denominado qualificação técnica. A deficiência na educação básica dos agricultores ou a falta dela dificultam a participação ativa no programa de integração, em função da ausência de conhecimento sobre temas como gestão e relações contratuais, bem como de capacitação técnica para assimilar as inovações tecnológicas exigidas pelo agronegócio. Constituídos, em sua maioria, por analfabetos e analfabetos funcionais, os agricultores encontram dificuldades para encaminhar suas demandas e exigir a garantia de seus direitos.

Conforme se observa, a falta de informação sobre a eficiência da governança na base das estruturas da agricultora familiar atua como força contrária à capacidade dos agricultores em operar mecanismos estratégicos para fazer frente às determinações hierárquicas superiores. Ciente desse cenário, a empresa utiliza como estratégia o diálogo direto com cada agricultor.

Sozinho, a gente não tem força para lutar contra uma empresa dessa. Um dia fui lá, para pedir explicação sobre o peso do meu coco. Cheguei lá diante da responsável pela parceria com os agricultores. Ela me tratou tão bem, me mandou sentar, serviu suco, conversou comigo sobre várias coisas e, no final, eu até esqueci o que eu fui fazer lá. Na empresa, são todos muito bem instruídos, e eu, que nem sei ler [...] é difícil (informação verbal).
A identificação dos fatores fulcrais de impacto indica que a expansão da lavoura do dendê na área pesquisada, tida como uma das possibilidades de recuperar áreas desflorestadas e promover o desenvolvimento local, não está atendendo às dimensões social e ambiental.

Não foi possível identificar nas comunidades pesquisadas um cenário propício à autonomia local, com ações de estímulo para o alcance de liberdades substantivas, condições essenciais para um processo de desenvolvimento local (Sen, 2010).

O que se verificou na região do "agronegócio do dendê" foi a formação de um espaço exposto às variáveis da economia globalizada, submetendo os indivíduos e os lugares aos nexos das dinâmicas externas e, de certa maneira, retirando-lhes o comando de suas decisões, num processo semelhante ao que vem se processando no sul do estado de Rondônia, com a inserção do "agronegócio" da soja, conforme analisado por Siva (2015).

Diante da questão posta, da escolha das atividades mais compatíveis com a realidade regional, constatou-se que o Projeto Dendê com base na integração da agricultura familiar não está apresentando resultados sustentáveis, mercê da incapacidade de superar o histórico "padrão de desenvolvimento", cujos reflexos marcam a realidade regional com alta concentração fundiária, expropriação das populações tradicionais e graves problemas socioeconômicos e ambientais.

\section{3. Índice de Sustentabilidade do \\ Desenvolvimento Local com base no dendê}

Com o intuito de avançar na interpretação dos fatores identificados, analisa-se o ISDL (Tabela 2). 
TABELA 2 - Índice de Sustentabilidade do Desenvolvimento Local, Pará, 2015

\begin{tabular}{lccc}
\hline \multicolumn{4}{c}{ ISDL $=$ Índice de Sustentabilidade do Desenvolvimento Local } \\
\hline IS $>0,7$ & $\begin{array}{c}\mathbf{N}^{\mathbf{0}} \text { de } \\
\text { agricultores }\end{array}$ & $\mathbf{( \% )}$ & Qualificação \\
$0,5<$ IS $\leq 0,7$ & 2 & $4 \%$ & Alto \\
$0,3<$ IS $\leq 0,5$ & 21 & $42 \%$ & Médio \\
IS $\leq 0,3$ & 26 & $52 \%$ & Baixo \\
Total & 1 & $2 \%$ & Muito baixo \\
\hline
\end{tabular}

FONTE: Dados da pesquisa. Elaboração própria.

Os resultados demonstraram que, na percepção de 4\% dos entrevistados, o ISDL foi considerado alto. Constituem uma pequena parcela dos agricultores com maior poder aquisitivo e renda diversificada, obtida de outras atividades, como a pecuária. Dispondo de maior visão de mercado, conseguiram apresentar bons níveis de produtividade. Além disso, estão realizando a compra de terras contíguas às suas, de agricultores em condições financeiras mais precárias.

$\mathrm{Na}$ percepção de $42 \%$ dos entrevistados, o índice foi considerado médio. Esses agricultores configuraram como de total abandono o ambiente operacional em que viviam antes do Projeto Dendê. Portanto, esse enquadramento pode ser considerado um progresso com relação às políticas de crédito, assistência técnica, treinamento, garantia de compra, enfim, o apoio desses órgãos, nunca antes visto no campo, foi um aspecto revelado como positivo.

Comparando a forma como a gente vivia aqui antes do dendê, nesses pontos melhorou bastante. A gente teve crédito no banco e isso nunca aconteceu aqui para nós. Mas, como lhe disse, tem muitos problemas também (informação verbal).

Sobre esse assunto, a então representante do Sindicato dos Trabalhadores Rurais de Moju fez a seguinte avaliação:
[...] Esses Pronafs são iniciativas muito boas. Agora liberaram o Pronaf Verde, além dos Pronafs Mulher e o Pronaf Jovem, mas aí eu pergunto: cadê o acesso? Infelizmente o Brasil é um país burocrático por demais. A gente manda a demanda e, agora, cadê a aprovação? [...] Ai chega um projeto desse como o dendê, que tem aprovação imediata, o pequeno agricultor vai de cabeça, sem considerar as consequências [...]. Se fosse investir na agricultura familiar da forma como deve ser, incluindo assistência técnica, acesso a crédito e tudo [...], nosso agricultor teria outro entendimento da coisa (informação verbal).

Os agricultores avaliaram de forma extremamente negativa os problemas relacionados à falta de transparência na pesagem e no valor da produção entregue à agroindústria e no valor cobrado por insumos como foices, sachos, machados, luvas e defensivos agrícolas, adquiridos junto à empresa, que são integralmente descontados dos valores devidos aos agricultores. Destacaram ainda a penosidade nas frentes de trabalho, o aumento no custo da produção com consequente diminuição da renda e a existência de uma relação de total subordinação e dependência dos agricultores aos ditames da empresa.

Foram apontados, ainda, problemas sociais como a precariedade das vias de transporte locais, dos serviços de saúde, educação, segurança, saneamento básico e o aumento da violência, agravados nos últimos anos, além dos impactos ambientais decorrentes da utilização de agrotóxicos nos dendezais, que contaminam os solos e as águas dos rios e igarapés que recortam a região, afetando a saúde nas comunidades (MPPA, 2014). Esses problemas são totalmente negligenciados pela empresa, que os considera de competência exclusiva do poder público.

Essas informações constam do relatório elaborado em 2014 pelo Instituto Observatório Social, quando da realização do levantamento sobre o com- 
portamento sociotrabalhista na produção de óleo de palma do dendê no estado do Pará (IOS, 2014).

Por fim, na percepção da maioria dos entrevistados (52\%), o índice foi classificado como baixo. Destacaram o processo contínuo de agravamento e piora de todos os aspectos mencionados anteriormente e o fato de estarem totalmente expostos aos possíveis riscos relacionados à perda da produção e ao aparecimento de pragas ou doenças, pois não há quaisquer cláusulas contratuais que os assegurem nesse sentido.

Outras queixas referem-se à incapacidade de gerenciamento do projeto diante do baixo grau de instrução da maioria dos agricultores e da ausência de uma ação direta de capacitação de seus filhos. A elevação dos custos inerentes ao cuidado com a área de terra da propriedade e a contratação de mão de obra terceirizada, visando cumprir as legislações ambiental e trabalhista, foram também mencionadas. Some-se a esse cenário a negligência no cumprimento das cláusulas contratuais ou mesmo a quebra contratual por parte da empresa, dado seu poder na tomada de decisão unilateral.

Para esse grupo, os direitos do agricultor resumiram-se à obrigação de cumprir, na íntegra, o que está previsto no contrato e as determinações adicionais que venham a ser impostas. Esse quadro é agravado pela ausência de fiscalização e acompanhamento do programa por parte dos órgãos governamentais competentes e ainda pela inércia das associações locais diante dos desmandos da empresa. Assim, o ambiente de conflito foi estabelecido, o que pode levar à ineficiência do processo de integração.

Comungam dessa opinião os $2 \%$ restantes, que avaliaram o índice como muito baixo e não reconhecem quaisquer melhorias atreladas ao dendê. "[...] aqui a gente se sente abandonado. A relação com a empresa só piora. Essa associação não nos serve de nada, só vem repassar para nós o que a empresa manda" (informação verbal).

Esse quadro reforça o entendimento de que o discurso de sustentabilidade da monocultura do dendê é eficiente e provocou uma espécie de apatia nas ações institucionais. Não foram criadas medidas de avaliação dos impactos gerados pela atividade sobre as dinâmicas sociais, econômicas e ambientais, dentro e no entorno das áreas nas quais se desenvolvem.

De modo geral, na percepção dos agricultores familiares, o ISDL foi considerado insuficiente para alavancar o desenvolvimento local e sustentável.

A forma como a agricultura familiar foi integrada à monocultura do dendê na região gerou um choque entre a racionalidade do grande capital e a da reprodução camponesa. O padrão econômico e de subsistência familiar está passando por uma reordenação socioeconômica, agora regida essencialmente pela lógica da economia de mercado, com amplos reflexos na base produtiva, no uso da terra, nas relações de trabalho e nas relações culturais com o território.

Trata-se da substituição da solidariedade orgânica, na qual as atividades são criadas e alimentadas com base nas ofertas do meio geográfico local e os agentes são considerados na sua contiguidade, pela solidariedade organizacional do capital (Santos \& Silveira, 2005; Sousa, 2015).

A avaliação negativa feita pelos agricultores demonstra que, embora tenham pouca instrução, esses sujeitos sociais têm o próprio entendimento sobre desenvolvimento, que não está circunscrito apenas aos mecanismos de mercado para promover crescimento econômico, mas envolve também o acesso a direitos básicos de cidadania e a liberdade para participar do mercado de forma mais equitativa. 
O conjunto dos aspectos avaliados como negativos para a sustentabilidade do desenvolvimento local constitui o que Sen (2010) classifica como privações das liberdades substantivas dos indivíduos. A persistência de tais privações dificulta a formação do agente livre e sustentável, que é motor fundamental do desenvolvimento.

Portanto, não foi possível associar o desenvolvimento sustentável com os componentes inclusão social e melhoria na qualidade de vida, pois as comunidades permanecem excluídas dos benefícios de uma vida mais digna, estão sendo diretamente impactadas no seu modo de vida e silenciosamente levadas a um processo de dependência excessiva da atividade de cultivo do dendê.

\subsection{Influências socioeconômicas e ambientais do Projeto Dendê}

O reconhecimento dos cinco fatores com impactos negativos apresentados na Tabela 1 contribuiu para a identificação de um cenário inédito sobre os rebatimentos socioeconômicos e ambientais do Projeto Dendê no processo de desenvolvimento local. Constituiu-se de pontos estratégicos para o planejamento de ações políticas, especialmente as de caráter coletivo para o enfrentamento das ameaças em curso no Baixo Tocantins.

A visão macro, configurada pelas dimensões sustentabilidade ambiental e mudança climática, revela um ambiente de ameaça extremamente desfavorável para as comunidades locais e envolve desafios que influenciam as escalas local, regional, nacional e global.

É preciso encarar com maior seriedade a busca por formas possíveis de coexistência de sistemas de utilização dos recursos naturais, com vistas a aliar a preservação do capital natural com os imperativos éticos.
Deve-se priorizar o desenvolvimento de tecnologia destinada ao manejo dos recursos naturais, para a prevenção e o controle do desmatamento e o tratamento dos resíduos agroindustriais que vêm contaminando rios e igarapés da região. Isso prescinde de um eficiente sistema de regulação, que preveja a intensificação da fiscalização na área, a adoção de valoração dos recursos naturais, a estimação das compensações por danos ambientais e as externalidades socioeconômicas negativas geradas pelo Projeto Dendê na região.

Nesse aspecto, a atuação das universidades locais é fundamental para a formação de especialistas e o desenvolvimento de tecnologia para gerar resultados sustentáveis no local. No campo científico, há uma demanda elevada por pesquisas a serem desenvolvidas em várias áreas, inclusive sobre o ciclo da palma, na perspectiva de não apenas explorar as vantagens comparativas do lugar, mas sim de construí-las (Becker \& Léna, 2002).

A compreensão mais diferenciada das diversas formas da agricultura familiar na Amazônia e o reconhecimento da possibilidade de essas formas de uso da terra serem bem mais sustentáveis econômica, ecológica e socialmente do que historicamente foram pensados, bem como podem inspirar políticas agrícolas favoráveis ao fortalecimento da agricultura familiar diversificada (Hurtienne, 2005).

É imprescindível o desenvolvimento de tecnologias apropriadas para atender aos desafios da sustentabilidade da agricultura familiar, considerando a realidade de carência em que as famílias estão inseridas e a formulação de políticas voltadas à qualificação e ao apoio técnico e financeiro para o fortalecimento da agricultura familiar diversificada. Até o momento não se buscou garantir as condições necessárias para induzir a diversificação da agricultura e assim reduzir a dependência excessiva das famílias da produção do óleo de palma. 
No ambiente microanalítico, situam-se as dimensões governança da cadeia, sustentabilidade social e qualificação técnica. Esse ambiente contempla forças sobre as quais os sujeitos participantes da cadeia exercem controle direto e, portanto, podem adotar ações imediatas para determinar os rumos da cadeia do dendê na região e, consequentemente, os seus rebatimentos no desenvolvimento local.

A pesquisa constatou que a estrutura de governança da cadeia produtiva do dendê constitui a dimensão mais problemática a ser enfrentada, pois é nela que estão concentrados os principais pontos de conflito entre os agricultores familiares e a empresa. Essa dimensão estabelece com as duas outras dimensões uma relação desigual, porém combinada.

É desigual à medida que a governança da cadeia é controlada de forma unilateral pela Agropalma, que impõe ao agricultor a lógica do comando e do controle, reduzindo a "responsabilidade social" ao cumprimento precário das cláusulas contratuais. E combinada porque essa lógica é necessária para garantir a acumulação de capitais pela agroindústria monocultora. O baixo nível de qualificação do produtor atua como força complementar nesse processo.

Não há interesse da Agropalma em estimular o fortalecimento das organizações sociais locais. A empresa privilegia o diálogo direto com cada produtor, priorizando as relações contratuais. $\mathrm{Na}$ verdade, esse é um requisito de defesa da empresa integradora. $\mathrm{O}$ enfraquecimento do poder de decisão das associações inibe o enfrentamento das demandas dos fornecedores da matéria-prima. As organizações existentes foram identificadas pelos agricultores como fortemente atreladas aos interesses da empresa.
[...] Um dia nós nos organizamos, fizemos uma greve para melhorar o preço do nosso coco, eles não receberam nenhum de nós lá. Essa associação não serve para nada, foi preciso o prefeito de Moju ir lá conversar com eles, mas não adiantou muito, não [...] (informação verbal).

O objetivo de promover mudanças de paradigma no desenvolvimento local por meio da cooperação entre Estado, iniciativa privada e pequenos agricultores não tem se mostrado exitoso com relação à "parceria" estabelecida entre a Agropalma e os agricultores familiares no Baixo Tocantins.

A cadeia produtiva do dendê conforma uma estrutura complexa de governança, pois integra vários atores em sua composição. Esse cenário evidencia um processo de cidadania que enfatiza direitos e responsabilidades como componentes de um consenso emergente na estrutura da governança. Com efeito, a governança deve estar ligada a uma preocupação com o capital social e com as bases sociais necessárias para o desempenho político e econômico efetivo, fundamentado na ação coletiva (Stoker, 2002).

Nesses termos, no âmbito da parceria já em curso entre agricultores e empresa integradora, é necessário garantir o envolvimento adequado daqueles na tomada de decisões, por meio de mecanismos decisórios participativos e não meramente consultivos e com filtragem representativa, como tem ocorrido. O papel dos atores locais em firmar alianças, estratégias e ações é uma forma de resistência para evitar que o agronegócio venha a se impor às práticas produtivas e aos modos de vida tradicionais (Backhouse, 2013).

Acredita-se que uma mudança de atitude por parte dos agricultores, dentro de uma perspectiva organizacional com vistas ao fortalecimento das associações locais ou à criação de cooperativas, poderá levá-los ao alcance de seus anseios e aspira- 
ções no espaço de conflito em que estão inseridos. A tomada de consciência de que são atores nesse processo e estão na arena providos de recursos e em igualdade de poder deve fazer parte das estratégias para o empoderamento dos pequenos agricultores vinculados à cadeia do dendê.

Entende-se, ainda, que tão importante quanto adotar medidas mitigadoras das externalidades socioeconômicas e ambientais negativas geradas pelo Projeto Dendê é o acompanhamento contínuo pelos diversos atores envolvidos no processo, a fim de que se possa avaliar a pertinência ou não dos caminhos adotados.

\section{Conclusões}

A expansão do dendê no Baixo Tocantins, com base na integração da agricultura familiar, está estruturada por cinco fatores socioeconômicos e ambientais com rebatimentos negativos na dinâmica do desenvolvimento local, segundo a percepção dos produtores integrados à Agropalma: governança da cadeia, sustentabilidade social, sustentabilidade ambiental, mudança climática e qualificação técnica.

A governança da cadeia no processo de integração entre a empresa e os agricultores locais tornou-se uma relação de dependência que caracteriza os agricultores como "funcionários terceirizados" por meio de contratos desfavoráveis ao alcance e a oportunidades dos agricultores.

O baixo grau de instrução da maioria dos agricultores e a ausência de uma ação direta de capaci- tação de seus filhos atuam como forças contrárias à capacidade daqueles em gerenciar o projeto $\mathrm{e}$ operar mecanismos estratégicos para fazer frente às determinações hierárquicas superiores.

A "responsabilidade social" da Agropalma limitou-se ao precário cumprimento dos termos estabelecidos nos contratos com os agricultores. Há um redirecionamento das demandas sociais para as esferas do Estado, como provedor do bem- estar social, demonstrando o descompromisso da empresa com a realidade local.

A configuração dos fatores sustentabilidade ambiental e mudança climática revelou um ambiente de ameaça para a manutenção de condições socioambientais adequadas à qualidade de vida na região. Desenvolvem-se em sentido contrário à perspectiva do desenvolvimento sustentável e inclusivo, indicando que as práticas produtivas nas plantações de dendê ocorrem fora de preceitos éticos e legais.

Por fim, o ISDL permitiu ratificar a incapacidade do dendê de tornar-se uma alternativa sustentável socioeconômica e ambientalmente, criando oportunidades de emprego, renda e melhoria na qualidade de vida das pessoas.

Sob essas condições, argumenta-se a necessária cautela antes de referendar esse tipo de investimento no meio rural amazônico, sobretudo na forma de integração vertical entre agroindústria e pequeno agricultor familiar como atividade inclusiva e sustentável capaz de contribuir significativamente para o fomento do desenvolvimento local. 


\section{Referências}

Acevedo, R. E. Territórios quilombolas face à expansão do dendê no Pará. In: Buenafuente, S. M. F. (Org.). Amazônia: dinâmica do carbono e impactos socioeconômicos e ambientais. Boa Vista: Ed. UFRR, 2010. p. 165-184.

Backhouse, M. A desapropriação sustentável da Amazônia: o caso de investimentos em dendê no Pará. Working Paper, Berlin, 6, 1-32, 2013. Disponível em: <http://www.fair-fuels.de/data/user/Download/Ver\%C3\%B6ffentlichungen/ FairFuels-Working_Paper_6_Portuguese.pdf $>$. Acesso em: dez. 2015.

Barquero, A. V. Desenvolvimento endógeno em tempos de globalização. Tradução de Ricardo Brinco. Porto Alegre: Fundação de Economia e Estatística, 2001.

Becker, B.; Léna, P. Pequenos empreendimentos alternativos na Amazônia. Rio de Janeiro: UFRJ; Rede de Sistemas Produtivos e Inovativos Locais, 2002. Disponível em: <http://www.ie.ufrj.br/redesist/NTF2/NT\%20bertha-philippe.pdf $>$. Acesso em: jun. 2012.

Börzel, T. A.; Risse, T. Governance without a State: can it work? Regulation \& Governance, 4, 113-134, 2010.

Brasil. Ministério da Agricultura, Pecuária e Abastecimento. Programa de Produção Sustentável de óleo de Palma no Brasil. Brasília, DF: MAPA, 2010. Disponível em:<http:// www.agricultura.gov.br/arq_editor/file/camaras_setoriais/ Palma_de_oleo/1_reuniao/Programa.pdf $>$. Acesso em: ago. 2014.

Drouvot, C. M.; Drouvot, H. O Programa Federal de Produção Sustentável de Óleo de Palma: a questão da participação dos atores locais em favor do desenvolvimento territorial. In: Anais do 2 Congrès Transformare. Paris, 19-20 de mar 2012.

Faucheux, S.; Noel, J. F. Economia dos recursos naturais e do meio ambiente. Lisboa: Instituto Piaget, 1995.

Feintreinie, L.; Chong, W. K.; Levang, P. Why do farmers prefer oil palm? Lessons Learnt from Bungo District, Indonesia. Small-Scale Forestry, 9, 379-396, 2010.

Hair Jr., J. F.; Anderson, R. E.; Tatham, R. L.; Black, W. C. Análise multivariada de dados. 6. ed. Porto Alegre: Bookman, 2009.
Hurtienne, T. P. Agricultura familiar e desenvolvimento rural sustentável na Amazônia. Novos Cadernos do NAEA, 8(1), 19-71, 2005.

IOS - Instituto Observatório Social. O comportamento sócio-trabalhista na produção de óleo de palma do dendê no Estado do Pará com foco nas empresas Agropalma, Biovale/Biopalma, Petrobrás Combustiveis. São Paulo: IOS, 2014. Disponível em: $<$ http://www.observatoriosocial.org. br/sites/default/files/05-07-2013_11-palma_dende-para_0. pdf $>$. Acesso em: fev. 2015.

McCarthy, J. F. Process of inclusion and adverse incorporation: oil palm and agrarian change in Sumatra, Indonesia. The Journal of Peasant Studies, 37(4), 2010.

MPPA - Ministério Público do Estado do Pará. Instituto Evandro Chagas detecta contaminação por agrotóxicos na Região de Expansão do dendê, 2014. Disponível em: <http://www.mppa.mp.br/index.php?action=Menu. interna\&id $=4380 \&$ class $=\mathrm{N}>$. Acesso em: mar. 2016.

Monteiro, K. F. G. Análise de indicadores de sustentabilidade em diferentes sistemas produtivos com palma de óleo no Estado do Pará. Belém, Tese (Doutorado em Ciências Agrárias) - UFRA, 2013.

Nahum, J. S.; Santos, C. B. dos. Dendeicultura e descampesinização da Amazônia paraense. Campo-Território. Revista de Geografia Agrária, 9, 469-485, 2014. Disponível em: $<$ http:www.seer.ufu.br/index.php/compoterritório/article/ view/23628/14394>.

Nahum, J. S.; Santos, C. B. dos. Impactos socioambientais da dendeicultura em comunidades tradicionais da Amazônia paraense. ACTA Geográfica, 63-80, 2013. doi: 10.5654/ actageo2013.0003.0004

Protocolo de intenções que celebram entre si, o Estado do Pará através da Secretaria Especial de Estado de Desenvolvimento Econômico e Incentivo à Produção (SEDIP), Secretaria de Estado de Agricultura (SAGRI), Secretaria de Estado de Meio Ambiente (SEMA), Programa Municípios Verdes (PMV), Empresa de Assistência Técnica e Extensão Rural (EMATER), Associação Brasileira de Produtores de Óleo de Palma (ABRAPALMA), Instituto de Terras do Pará (ITERPA), Federação da Agricultura e Pecuária do Estado do Pará (FAEPA), Serviço Nacional de Aprendizagem Rural 
(SENAR), Banco da Amazônia (BASA), Banco do Estado do Pará (BANPARÁ), e demais instituições financeiras que declararam adesão a este PROTOCOLO e demais empresas de palma atuantes no Pará que declararem adesão a este PROTOCOLO, 2014. Disponível em: <http://www. abrapalma.org/downloads/Protocolo_Palma.pdf $>$. Acesso em: jan. 2015.

Pye, O. Nachhaltige Profitmaximierung. Der Palmöl-Industrielle Kompex und die Debatte um "nachhaltige Biotreibstoffe". Peripherie, 112(28), 429-455, 2008.

Rawls, J. Political Liberalism. New York: Columbia University Press, 2005.

Santana, A. C. de. Elementos da economia, agronegócio e desenvolvimento local. Belém: GTZ; TUD; UFRA, 2005.

Santana, A. C. de; Santana Á. L. de; Santana, Á. L. de; Costa, N. L.; Nogueira, A. K. M. Planejamento estratégico de uma universidade federal na Amazônia: aplicação da análise fatorial. Revista de Estudos Sociais, 16(32), 183, 2014.
Santos, M.; Silveira, M. L. O Brasil: território e sociedade no início do século XXI. 8. ed. Rio de Janeiro: Record, 2005.

Sen, Amartya. Desenvolvimento como liberdade. Tradução de Laura Teixeira Motta. São Paulo: Companhia das Letras, 2010.

Silva, R. G. C. Amazônia Globalizada: da fronteira agrícola ao território do agronegócio - o exemplo de Rondônia. Confins, 23, 2015. Disponível em: $<$ https://confins.revues. org/9949>.

Sousa, C. F. M. Projetos de desenvolvimento para a Amazônia: a expansão da dendeicultura. In: Anais do Seminário Internacional América Latina, 2015. GETTAM/NAEA/ UFPA. Belém, 09-11 de nov., 2015.

Stoker, G. Governance as Theory: five propositions. Oxford: Blackwell; Unesco, 17-28, 1998.

Vasconcelos, A. M.; Vasconcelos S. M. Alternativas de desenvolvimento e o modelo de sustentabilidade: um estudo de caso das organizações locais dos municípios de Barcarena e Igarapé-Miri. Belém: UNAMA/FIDESA, 2007. 